\title{
FORMAÇÃO DE PROFESSOR: O CONCEITO DE INTERAÇÃO EM TEXTOS DE ALUNOS DO $4^{\circ}$ ANO DE LETRAS/ESPANHOL
}

\author{
TEACHER TRAINING: INTERACTION CONCEPT IN STUDENTS' TEXTS OF SPANISH \\ LANGUAGE COURSE $\left(4^{\text {TH }}\right.$ ACADEMIC YEAR).
}

\author{
Marcela de Freitas Ribeiro Lopes \\ marcelamail@yahoo.com.br
}

\begin{abstract}
Resumo:
Esta pesquisa pretende apresentar e investigar conceitos do termo Interação presentes em textos de alunos do $4^{\circ}$ ano de Letras/Espanhol da Universidade Estadual do Centro-Oeste do Paraná UNICENTRO/ Campus de Irati. Pedi aos alunos que escrevessem sobre professores que marcaram suas vidas na escola exemplificando as atitudes desses professores. Nestes textos, percebo que os alunos abordam, mesmo que inconscientemente, características da Interação tanto em relação ao conceito de Vygotsky, como também de Bakhtin. Para fundamentar a pesquisa abordarei os conceitos vygotskyanos sobre interação e sobre internalização, e os conceitos bakhtinianos de interação, principalmente no que diz respeito aos termos: dialogismo e interação verbal. É certo que esses conceitos não aparecem claramente nos textos estudados, porém estão presentes nos exemplos dados e no senso comum dos alunos a respeito da ação do professor. Os alunos criticam um ensino que não privilegia a interação, e dizem também que é muito difícil fugir do tradicional. Desta maneira relacionam o tradicional a tudo aquilo que "não é comunicativo" e "não é interação".
\end{abstract}

Palavras-chave: formação de professor, teoria/prática, interação.

Abstract:

This project intends to show and to do a research on concepts of the term interaction present in $4^{\text {th }}$ academic year Spanish Language students' texts of UNICENTRO/ Campus Irati. I asked for my students to write about their most important teachers in their school lives and to point an example of their teachers' attitude at class. Their texts showed that they deal with some characteristics of interaction concepts by Vygotsky and Bakhtin. To justify this research I deal with the concepts of Vygotsky those talks about interaction and the concepts of Bakhtin those talks about dialogism and verbal interaction. With certain these concepts doesn't appear obvious in the studied texts, but they are present in the examples and common sense of the students. These students criticize a teaching that doesn't privileges the interaction and says that is to hard to run away from traditional teaching. So they link the traditional to everything that is not communicative or that is not interaction.

Key words: teacher training, theory/ practice, interaction.

\section{Introdução}

Esta pesquisa apresenta e investiga conceitos bakhtinianos e vygotskianos de interação, que alunos, do último ano do curso de Letras/ Espanhol da UNICENTRO Campus 
de Irati, apontaram em textos escritos sobre experiências com antigos professores e sobre ensino-aprendizagem.

Para a realização deste trabalho, optamos por uma pesquisa qualitativa na modalidade de Estudo de Caso. O corpus foi coletado em uma disciplina que ministrei da grade curricular do curso de Letras Espanhol dessa Universidade, e faz parte de um projeto maior de pesquisa. Os textos escritos foram analisados, aqui, e reconhecemos neles, características da Interação tanto em relação ao conceito de Vygotsky, como também de Bakhtin. É certo que esses conceitos não aparecem claramente nos textos analisados, porém estão presentes nos exemplos dados e no senso comum e científico dos alunos a respeito da ação do professor.

\section{Conceitos de Vygotsky e Conceitos de Bakhtin}

Para aclarar e fundamentar a análise é necessário retomar alguns conceitos dos dois autores mencionados na pesquisa. Esses autores, aqui, serão abordados juntos, já que vejo a importância da vinculação de suas teorias para o ensino-aprendizado, e, também, porque acredito que haja uma relação possível entre eles. Essa aproximação de teorias de Vygotsky e Bakhtin é manifesta por diversos autores como Garcez 1998, Freitas 2005, Cardoso 2002, Souza, 2003.

Vygotsky trabalha com questões de ensino percorrendo um trajeto que vai do social para o individual. Um termo importante tratado por ele é a ZDP - Zona de desenvolvimento proximal. Essa abordagem é a:

distancia entre o nível de desenvolvimento real, que se costuma determinar através da solução independente de problemas, e o nível de desenvolvimento potencial, determinado através da solução de problemas sob a orientação de um adulto ou em colaboração com companheiros mais capazes ( VYGOTSKY, 1988, p.97).

Para Vygotsky ZDP é o trabalho com o conhecimento que já está amadurecido/internalizado e, portanto, a criança consegue desenvolver sozinha; em relação com o novo conhecimento que será construído na interação com outro indivíduo. A interação é essencial no processo de aprendizado, pois, para o autor, aprendizado é de natureza social. 
A linguagem acompanha o aprendizado, já que é na interação entre criança e as pessoas no seu ambiente social que esse se desenvolve. A fala interior e o pensamento reflexivo também são desenvolvidos na interação. O percurso até a fala interior é chamado de internalização, ou seja, "reconstrução interna de uma operação externa" (VYGOTSKY, 1988, p. 63).

O processo de internalização acontece do Interpessoal para o Intrapessoal transformando a atividade sócio-histórica externa em interna. Esse desenvolvimento de internalização acontece também na linguagem, pois "aspectos tanto da fala externa ou comunicativa como da fala egocêntrica "interiorizam-se", tornando-se a base da fala interior" (VYGOTSKY, 1988, p.65).

Esse evento ocorre ao longo do desenvolvimento e não é um processo automático e rápido, portanto o autor discute questões manifestando o caráter temporal e apontando que é crucial um progresso de sedimentação no aprendizado.

Para Bakhtin a linguagem também é de natureza social. Portanto o autor discute aspectos de Interação verbal apontando que a enunciação é "produto da interação de dois indivíduos socialmente organizados" (BAKHTIN, 1988, p. 112).

Já que a linguagem se constitui socialmente, a palavra é "produto da interação do locutor e do ouvinte" (BAKHTIN, 1988, p. 113), sendo assim, a comunicação está sempre vinculada com a interação dentro de um contexto sócio-histórico, pois "a comunicação verbal não poderá jamais ser compreendida e explicada fora desse vínculo com a situação concreta" (BAKHTIN, 1988, p.124).

A palavra expressa relação/interação entre um indivíduo e "outro". Esse "outro" tem papel relevante na teoria de Bakhtin, já que, para o autor, a linguagem acontece sempre na interação, ou seja, sempre se estabelece dialógicamente, mesmo quando parece ser monológica, pois nesse caso a interação é determinada pelo diálogo com o outro de si próprio.

Já que o outro, o interlocutor é importantíssimo, é quem determina a linguagem na interação, a atitude responsiva ativa do interlocutor, proposta por Bakhtin, vem a firmar a interação, ou seja,

o ouvinte, ao perceber e compreender o significado (lingüístico) do discurso, ocupa simultaneamente em relação a ele uma ativa posição responsiva: concorda ou 
discorda dele (totalmente ou parcialmente), completa-o, aplica-o, prepara-se para usá-lo, etc (BAKHTIN, 2003, p. 271).

O interlocutor, na interação verbal, completa, aplica, prepara, para usar a linguagem elaborada numa resposta ou contra-palavra, que pode até ser muda ou de efeito retardado, porém transforma palavra do outro em própria palavra num elo comunicativo de alternância de sujeitos estabelecendo a comunicação na interação verbal.

Esses conceitos bakhtinianos sobre linguagem, quando incorporados ao ensino de línguas, determinam um enfoque que caracteriza-se por deslocar o professor de uma postura detentora do conhecimento para um papel de mediador. E os alunos de uma postura passiva para uma postura ativa na interação com a linguagem e com o mundo.

\section{Análise dos dados}

O trabalho de campo foi realizado na Universidade Estadual do Centro-Oeste do Paraná, Unicentro, no campus de Irati, no ano de 2005, com um grupo de 7 alunos do $4^{\circ}$ ano de Letras/ habilitação Espanhol. O currículo do curso de Letras dessa universidade é anual e contempla quatro anos, portanto, estes alunos estavam no último ano de suas formações.

Os dados foram coletados na disciplina que ministrei, de Estágio Supervisionado de Língua Espanhola. Pedi aos alunos, nos primeiros dias do ano letivo, que escrevessem sobre professores que marcaram positiva ou negativamente suas vidas durante a escola e/ou graduação. Pedi também que não mencionassem nomes, mas se preocupassem com as ações desses professores, fazendo relações com suas futuras práticas. Meu objetivo, em relação a essa tarefa, era recapitular seus textos no final do ano e refletir sobre concepções de língua/ensino/aprendizagem. Assim, os alunos iriam refletir sobre seus enfoques metodológicos do começo ao final do ano, após cumprirem o estágio de regência, analisando então o processo deles na disciplina. Os textos foram escritos e meus objetivos, na disciplina, alcançados.

Aqui, neste artigo, os mesmos textos serão explorados no sentido de reconhecer conceitos de Bakhtin e Vygotsky sobre Interação. Portanto, nesta fase de análise dos dados, pretendo depreender, com base na teoria exposta, e a partir de uma análise qualitativa de dados, os conceitos abordados, contextualizando e estabelecendo relações entre os dois 
teóricos mencionados.

Analisarei, então, 7 textos, dos 7 alunos mencionados, cujos nomes foram trocados por motivos de ética profissional e, também, pelo fato de não ter como objetivo aqui analisar o aluno " $x$ ", e sim, analisar como aparecem conceitos como "atitude responsiva ativa", "internalização", "interação", nos textos dos alunos do último ano de graduação em Letras/Espanhol, ou seja, de uma maneira coletiva, analisar como que o grupo, de futuros professores, aborda tais conceitos, provavelmente vistos em algumas disciplinas da graduação.

Inicialmente, levantei alguns itens comuns nos dados analisados e os dividi em dois momentos: Ação positiva, na qual os alunos apontam as histórias de professores que marcaram suas vidas na escola positivamente, com exemplos e com expectativas futuras de modelos a ser seguido; e Ação negativa, na qual os alunos apontam ações de exprofessores de forma negativa mencionando modelos a não serem seguidos.

\subsection{Ação positiva}

Os alunos abordam ações que consideram serem eficientes no processo de ensinoaprendizagem, e, nesses textos vejo mencionados conceitos de interação, zona de desenvolvimento proximal, outro, internalização e atitude responsiva ativa.

Me gustaría ser, además de profesora, amiga de mis alumnos, una persona que puede ayudarles en los momentos que necesiten. Quiero enseñarles a gustar del español, a interesarse por la lengua, ministrando clases en que ellos puedan participar, con métodos que les sean interesantes, y que les hagan descubrir cosas respecto a la lengua, interpretando, pesquisando, o sea, buscando y construyendo el aprendizaje, no solos, sino interactuando con profesor y colegas, desarrollando las cuatro habilidades lingüísticas, haciendo actividades que les permitan poco a poco, conseguir, de verdad, comunicarse en español." (Yolanda)

"siempre preparaba clases que llevaba a los alumnos tener interés y a participar de sus clases" (José)

“Todavía, aprender una lengua no significa aprender sólo reglas, pero si las culturas 
de un pueblo, los costumbres, y también conocer como vive una persona distinta de nosotros. Para una buena comprensión y un bueno aprendizaje, el profesor debe presentar temas que hagan parte de la realidad, o sea, de la vida cotidiana de los estudiantes." (Manuela)

"Ella enseñaba de un modo muy divertido, en que la mayoría conseguía comprender lo pretendido. La profesora trabajaba con la parte estructural de la lengua a través de las redacciones que escribíamos en que ella pedía asuntos acerca de la realidad. Eso hacía con que nosotros supiéramos lo que escribir, y buscando de manera indirecta utilizarse de la parte gramatical de la lengua" (Estela)

Quando os alunos futuros-professores dizem "ministrando clases en que ellos puedan participar", "no solos, sino interactuando con profesores y colegas", "interés y a participar de sus clases", eles estão reportando conceitos de interação de Bakhtin e de Vygotsky, pois, os dois autores partilham da concepção social de interação.

Vygotsky teoriza sobre a zona de desenvolvimento proximal, na qual a interação acontece no processo de ensino na relação criança e adulto ou criança e "companheiros mais capazes". Ou seja, interação com professor e com colegas, participação nas aulas, como citam os alunos.

Bakhtin teoriza sobre a interação verbal entre dois indivíduos socialmente organizados, explorando o elo entre locutor e ouvinte. O "outro" e a contra-palavra remetem a participação ativa na comunicação, abordada pelos graduandos quando estes se referem à participação na sala de aula.

Vinculado à questão do outro e da participação, encontra-se o conceito de atitude responsiva ativa e de internalização. Quando os alunos dizem: "y que les hagan descubrir cosas respecto a la lengua, interpretando, pesquisando, o sea, buscando y construyendo el aprendizaje, no solos, sino interactuando", “desarrollando las cuatro habilidades lingüísticas, haciendo actividades que les permitan poco a poco, conseguir, de verdad, comunicarse en español", "ella enseñaba de un modo muy divertido, en que la mayoría conseguía comprender lo pretendido", "eso hacía con que nosotros supiéramos lo que escribir".

Para Bakhtin atitude responsiva ativa é quando o interlocutor, na interação verbal, completa, aplica, prepara, para usar a linguagem elaborada numa resposta ou contra- 
palavra, ou seja, no momento que os futuros-professores usam os verbos pesquisar, buscar, construir, compreender e saber o que escrever (contra-palavra), eles estão tendo ou buscando atitudes responsivas. Esse processo que pode ser demorado e, para o autor, de efeito retardado. Nesse sentido encontra-se a relação com internalização e sedimentação temporal de internalização de Vygotsky, já que para o autor este processo que vai do exterior para o interior busca compreensão e atitude responsiva e o resultado vai estar na contrapalavra dos aprendizes, nos textos e na capacidade de se comunicar.

Todos esses conceitos são expostos pelos alunos direcionando a um enfoque de ensino-aprendizagem que visa a interação, a uma concepção de língua de natureza social, e com isso prioriza a contextualização no ensino, ou seja, uma das preocupações dos alunos é apresentar aulas que façam parte da vida e da realidade dos alunos.

\subsection{Ação negativa}

Os alunos abordam ações negativas de professores que são autoritários e que não conseguem que os alunos compreendam/ aprendam; portanto, os alunos dizem "não querer ser" esse tipo de professor. Quando apresentam os textos sobre esse tema, os alunos apontam conceitos de sedimentação temporal, natureza social da língua, atitude responsiva, interação, interação, internalização.

"No me gustaría ser aquel profesor que no admitía que los alumnos hiciesen preguntas mientras sus clases; mientras las pruebas, el profesor dejaba los alumnos nerviosos y, los mismos, no alcanzaban resultados buenos; en la prueba, si el alumno erraba poca cosa de una cuestión, el profesor desconsideraba toda la cuestión." (José)

"El profesor que nunca me gustó y por esto no quiero parecerme es aquél profesor aburrido, autoritario, que se pone arriba de los alumnos como si fuera el dueño de la verdad y entonces empieza a dictar reglas gramaticales y llenar la pizarra con ejercicios de repetición, sin ninguna referencia o contexto donde puedan intentar situarse. O aquél que no acepta que nadie hable, ni siquiera le hagan preguntas, que sean solamente repetidores, así como hacian los profesores tradicionales." (Yolanda) 
"Creo que cuando el profesor es tradicional la clase se queda aburrida, o sea, llega y pide que copien de la pizarra, o que leían el texto y repitan las palabras que encuentran dificultad en la pronuncia. No es este tipo de profesora que yo quiero ser." (Maria)

"A mí no me gustaría ser un profesor autoritario, nadie puede hablar nada que solo él tiene la palabra El profesor necesita reflexionar su manera de enseñar la lengua extranjera, analizar y evaluar las prácticas de aula e iniciar cambios en la misma. A mí no me gustaría ser un profesor tradicional, que use solamente la gramática, enseñar apenas las reglas gramaticales, y no dedicarse en estudiar para dar clases" (Manuela) "Ya la experiencia con la profesora de geografía que tuve mientras estudiaba la enseñanza fundamental no fue tan buena, pues ella no decía nada acerca del tema propuesto en el libro que teníamos como referencia. Sólo era necesario hacer copias de cuestiones que estaban al fin del capítulo y ella mismo daba las instrucciones diciéndonos en cual página y párrafo estaba la respuesta. En esta época nos poníamos muy a gusto pues era como si fuera una clase vaga. Pero hoy es posible ver como este tipo de enseñanza perjudica el aprendizaje del alumno". (Estela)

Os futuros-professores abordam os mesmo conceitos do item anterior, porém aqui, os conceitos são apresentados no sentido de negar um ensino que não os leva em consideração. Por exemplo, quando os alunos remetem a natureza social dizendo que "no me gustaría ser aquel profesor que no admitía que los alumnos hiciesen preguntas mientras sus clases", "llenar la pizarra con ejercicios de repetición, sin ninguna referencia o contexto donde puedan intentar situarse. $O$ aquel que no acepta que nadie hable, ni siquiera le hagan preguntas", "nadie puede hablar nada que sólo él tiene la palabra". Fica claro que os alunos remetem a um ensino que não leva em consideração os conceitos de Bakhtin e Vygotsky de interação.

A questão da sedimentação temporal é retomada quando o graduando diz que o professor não aceita que os alunos errem algo de um exercício, tem que acertar todo o exercício, ou seja, não existe o tempo de internalização, a aprendizagem é rápida e imediata.

Os futuros-professores abordam um ensino tradicional, que se desenvolve através de cópia, regras e repetição, no qual o professor deixa os alunos nervosos, é autoritário, dono 
da verdade. Nesse ensino e nesse professor tradicional, não se menciona internalização, atitude responsiva, interação, o outro no processo de interação na linguagem.

\section{Conclusão}

Para concluir, pude perceber que os alunos demonstram conceitos, difundidos hoje, que prioriza por uma concepção de língua como interação e ensino-aprendizagem como processo de construção na interação. Esse enfoque nega o ensino de língua direcionado a ensinar sistema de regras, cópia ou transmissão de conhecimento, que para os graduandos é nomeado como ensino tradicional.

Os futuros-professores trabalharam com práticas para definir conceitos teóricos. Porém esses conceitos não foram citados e contextualizados teoricamente pelos alunos, por dois motivos: 1. por não ter sido esse o objetivo do texto, 2. pelo fato da teoria não ser consciente para os graduandos.

$\mathrm{Na}$ formação de um professor de Língua Espanhola é importante que ele seja capaz de relacionar teoria e prática, já que estas estão completamente vinculadas e inseparáveis. Portanto, formar professores capazes de na prática repetir e aceitar teorias divulgadas em parâmetros, livros e manuais não condiz com o objetivo do curso de Letras/Licenciatura. Estudar para exercer o magistério na área de Letras/Línguas Estrangeiras é questionar, refletir sobre teorias e entender como se dá o elo entre teoria e prática.

\section{Referência bibliográfica}

BAKHTIN, M.; VOLOCHINOV, V.N. Marxismo e filosofia da linguagem. 6.ed. São Paulo: Hucitec, 1992.

BAKHTIN, M. Estética da criação verbal. São Paulo: Martins Fontes, 2003.

CARDOSO, C. J. A socioconstrução do texto escrito: uma perspectiva longitudinal. Campinas, SP: mercado das Letras, 2002. 
FREITAS, M. T. A. Nos textos de Bakhtin e Vygotsky: um encontro possível. In: BRAIT, B. (org.) Bakhtin, dialogismo e construção do sentido. 2.ed. Campinas: Unicamp, 2005.

GARCEZ, L. A escrita e o outro: os modos de participação na construção do texto. Brasília: UNB, 1998.

SOUZA, L. V. As proezas das crianças em textos de opinião. Campinas, SP: Mercado das Letras, 2003.

VYGOTSKY, L. S. A formação social da mente. 2.ed. São Paulo: Martins Fontes, 1988. 